\title{
Homocoupling of aryl iodides promoted by nickel(0) nanoparticles
}

\author{
Francisco Alonso*, Paola Riente, and Miguel Yus* \\ Departamento de Química Orgánica and Instituto de Síntesis Orgánica (ISO), Facultad de \\ Ciencias, Universidad de Alicante, Apartado 99, E-03080 Alicante, Spain \\ E-mail:falonso@ua.es,yus@ua.es
}

\begin{abstract}
This paper is dedicated to Professor Irina P. Beletskaya on the occasion of her $75^{\text {th }}$ birthday
\end{abstract}

\begin{abstract}
Nickel(0) nanoparticles generated by the reduction of anhydrous $\mathrm{NiCl}_{2}$ with $\mathrm{Li}$ and a catalytic amount of a polymer-supported arene have been found to promote the homocoupling of aryl iodides, in the presence or absence of a ligand, under relatively mild reaction conditions.
\end{abstract}

Keywords: Aryl iodides, homocoupling, nickel, nanoparticles

\section{Introduction}

Since its discovery more than a century ago, the aryl-aryl bond formation ${ }^{1}$ has attracted the interest of many research groups because these bonds are very often found in natural products as well as in numerous biologically active compounds of synthetic origin. Biaryls can be also found in commercial dyes, in polyaromatics with applications as organic conductors or semiconductors, and in ligands for asymmetric catalysis.

Although copper was almost the only metal usable for aryl-aryl bond formation for a long time, nowadays palladium catalysts are much more used than their copper or even nickel counterparts. ${ }^{1}$ Thus, the palladium-catalyzed reductive coupling of aryl halides (analogous to the Ullman reaction) is the most studied reaction to obtain symmetrical biaryls. ${ }^{2}$ In recent years, much effort has been dedicated to this transformation by the introduction of non-conventional methodologies. ${ }^{3}$ Nonetheless, nickel (cheaper than palladium) has been used as an alternative metal for the homocoupling of aryl halides either in stoichiometric ${ }^{4}$ or catalytic amounts, ${ }^{5}$ in the latter case in the presence of a stoichiometric amount of a reducing agent.

On the other hand, we have recently reported the fast synthesis of nickel(0) nanoparticles with diameters of $2.5 \pm 1.5 \mathrm{~nm}$ by reduction of anhydrous nickel(II) chloride with lithium powder and a catalytic amount of DTBB (4,4'-di-tert-butylbiphenyl, as an electron carrier) in THF at 
room temperature. ${ }^{6}$ The high reactivity of these nanoparticles was demonstrated in the catalytic hydrogenation and reduction of a variety of organic compounds, including carbon-carbon multiple-bond-containing compounds. ${ }^{7,8}$ Moreover, reduction systems similar to $\mathrm{NiCl}_{2}$ - $\mathrm{Li}$ DTBB(cat.), such as $\mathrm{NiCl}_{2}$-Li-copolymer(cat.), ${ }^{7 \mathrm{~b}} \mathrm{NiCl}_{2} \cdot 2 \mathrm{H}_{2} \mathrm{O}$-Li-DTBB(cat.), ${ }^{8} \mathrm{NiCl}_{2}$-LiDTBB(cat.)-EtOH, or $\mathrm{NiCl}_{2}$-Li-copolymer(cat.)-EtOH, also generate nanosized metallic nickel. ${ }^{9}$ In particular, the two latter systems have found application in the highly selective conjugate reduction of $\alpha, \beta$-unsaturated carbonyl compounds ${ }^{10}$ as well as in the stereoselective cis semihydrogenation of internal alkynes and the semihydrogenation of terminal alkynes under mild reaction conditions. ${ }^{11}$

In an attempt to expand the application of the above mentioned nickel(0) nanoparticles, we decided to explore their reactivity in carbon-carbon coupling reactions starting from the simplest one, the homocoupling of aryl halides. Herein, we want to report our results on the reductive homocoupling of aryl iodides promoted by in situ generated nickel(0) nanoparticles.

\section{Results and Discussion}

The nickel(0) nanoparticles were generated from anhydrous $\mathrm{NiCl}_{2}, \mathrm{Li}$ powder, a catalytic amount of DTBB, and EtOH in THF. In order to optimize the reaction conditions, $p$-iodotoluene was used as a model starting material (Scheme 1). The effect of the base, ligand, solvent, temperature and reaction time is shown in Table 1. Three blank experiments revealed that the presence of nickel was indispensable for the homocoupling to occur and that only a trace of product was obtained in the absence of a base or in the simultaneous absence of a base and a ligand.

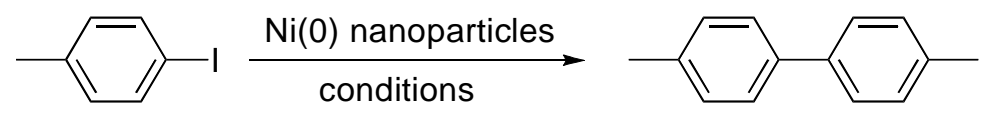

\section{Scheme 1}

Generated in situ from $\mathrm{Li}$ and EtOH, LiOEt performed better as a base than any of the inorganic bases tested, independent of the rest of the parameters varied. The nitrogen-containing ligands 1,10-phenanthroline and 4,7-diphenyl-1,10-phenanthroline (bathophenanthroline) gave much better yields than triphenylphosphane or tricyclohexylphosphane (compare entries 1 and 3 with 10 and 11, Table 1). However, the reaction with bathophenanthroline was faster than with phenanthroline, giving the expected biphenyl in higher yield (compare entries 10 and 11, Table 1). Although refluxing in THF (the solvent in which the nanoparticles were generated) seemed to be appropriate for the homocoupling reaction, some solvent combinations were studied in order to improve the yield or to shorten the reaction times. Thus, the THF-dioxane (1:2) combination at $110{ }^{\circ} \mathrm{C}$ showed similar results to those with THF (compare entries 11 and 17, Table 1). The THF-DMF (1:2) solvent system at a much higher temperature considerably reduced the reaction times but did not improve the yields (compare entries 1, 3 and 11 with 19, 20 and 21, 
respectively, Table 1). Only in the presence of water the reaction proceeded at room temperature albeit with low conversion (Table 1, entries 22-24), whereas traces of the product were obtained at $100{ }^{\circ} \mathrm{C}$ (Table 1, entry 25). Good yield of the biaryl product was obtained in the absence of a ligand in THF, though the reaction time was longer than in the presence of bathophenanthroline (Table 1, entries 11 and 26).

Table 1. Homocoupling of $p$-iodotoluene promoted by nickel(0) nanoparticles ${ }^{\mathrm{a}}$

\begin{tabular}{|c|c|c|c|c|c|c|}
\hline Entry & Base $^{b}$ & Solvent & Ligand $^{\mathrm{C}}$ & $\mathrm{T}\left[{ }^{\circ} \mathrm{C}\right]$ & $\mathrm{t}[\mathrm{h}]$ & 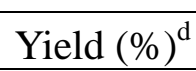 \\
\hline 1 & $\mathrm{LiOEt}$ & THF & $\mathrm{PPh}_{3}$ & 76 & 48 & 43 \\
\hline 2 & $\mathrm{~K}_{3} \mathrm{PO}_{4} \cdot \mathrm{H}_{2} \mathrm{O}$ & THF & $\mathrm{PPh}_{3}$ & 76 & 48 & trace \\
\hline 3 & LiOEt & THF & $\mathrm{PCy}_{3}$ & 76 & 24 & 43 \\
\hline 4 & $\mathrm{~K}_{3} \mathrm{PO}_{4} \cdot \mathrm{H}_{2} \mathrm{O}$ & THF & $\mathrm{PCy}_{3}$ & 76 & 24 & 11 \\
\hline 5 & $\mathrm{Na}_{2} \mathrm{CO}_{3}$ & THF & $\mathrm{PCy}_{3}$ & 76 & 48 & 10 \\
\hline 6 & LiOEt & $\mathrm{THF}$ & bipyridine & 76 & 48 & 36 \\
\hline 7 & $\mathrm{~K}_{3} \mathrm{PO}_{4} \cdot \mathrm{H}_{2} \mathrm{O}$ & $\mathrm{THF}$ & bipirydine & 76 & 48 & 26 \\
\hline 8 & $\mathrm{Na}_{2} \mathrm{CO}_{3}$ & THF & bipyridine & 76 & 48 & 4 \\
\hline 9 & $\mathrm{Cs}_{2} \mathrm{CO}_{3}$ & THF & bipyridine & 76 & 48 & trace \\
\hline 10 & LiOEt & THF & phenanthroline & 76 & 48 & 67 \\
\hline 11 & LiOEt & THF & bathophenanthroline $\mathrm{e}^{\mathrm{e}}$ & 76 & 12 & 90 \\
\hline 12 & $\mathrm{~K}_{3} \mathrm{PO}_{4} \cdot \mathrm{H}_{2} \mathrm{O}$ & THF & bathophenanthroline & 76 & 48 & 60 \\
\hline 13 & $\mathrm{Na}_{2} \mathrm{CO}_{3}$ & THF & bathophenanthroline & 76 & 48 & 11 \\
\hline 14 & $\mathrm{Cs}_{2} \mathrm{CO}_{3}$ & THF & bathophenanthroline & 76 & 48 & trace \\
\hline 15 & LiOEt & THF-dioxane 1:2 & $\mathrm{PCy}_{3}$ & 110 & 24 & 30 \\
\hline 16 & $\mathrm{~K}_{3} \mathrm{PO}_{4} \cdot \mathrm{H}_{2} \mathrm{O}$ & THF-dioxane 1:2 & РСу & 110 & 24 & trace \\
\hline 17 & LiOEt & THF-dioxane 1:2 & bathophenanthroline & 110 & 24 & 85 \\
\hline 18 & $\mathrm{~K}_{3} \mathrm{PO}_{4} \cdot \mathrm{H}_{2} \mathrm{O}$ & THF-dioxane 1:2 & bathophenanthroline & 110 & 24 & 34 \\
\hline 19 & LiOEt & THF-DMF 1:2 & $\mathrm{PPh}_{3}$ & 140 & 6 & 29 \\
\hline 20 & LiOEt & THF-DMF 1:2 & $\mathrm{PC}_{3}$ & 140 & 6 & 22 \\
\hline 21 & LiOEt & THF-DMF 1:2 & bathophenanthroline & 140 & 6 & 56 \\
\hline 22 & $\mathrm{LiOEt}$ & THF- $\mathrm{H}_{2} \mathrm{O} 3: 4$ & РСуз & $\mathrm{rt}$ & 48 & 16 \\
\hline 23 & $\mathrm{LiOEt}$ & THF- $\mathrm{H}_{2} \mathrm{O} 3: 4$ & bathophenanthroline & $\mathrm{rt}$ & 48 & trace \\
\hline 24 & $\mathrm{LiOEt}$ & THF- $\mathrm{H}_{2} \mathrm{O} 3: 4$ & - & $\mathrm{rt}$ & 48 & 10 \\
\hline 25 & LiOEt & THF- $\mathrm{H}_{2} \mathrm{O} 3: 4$ & $\mathrm{PCу}_{3}$ & 100 & 48 & trace \\
\hline 26 & LiOEt & THF & - & 76 & 24 & 88 \\
\hline
\end{tabular}

${ }^{\mathrm{a}} \mathrm{Ni}(0)$ nanoparticles were generated from $\mathrm{NiCl}_{2}(1 \mathrm{mmol})$, Li powder $(2 \mathrm{mmol})$, and DTBB $(0.05 \mathrm{mmol})$ in THF (4 $\mathrm{mL})$ at rt.

b 2 mmol of base. LiOEt was generated in situ from additional Li powder (2 mmol) and EtOH (2 mmol).

c 10 mol\% ligand.

${ }^{\mathrm{d}}$ GLC yield.

e 4,7-Diphenyl-1,10-phenanthroline. 
The best reaction conditions involving LiOEt, bathophenanthroline, and THF at reflux were applied to a variety of differently substituted aryl iodides (Table 2). In these reactions, however, a polymer-supported arene, ${ }^{7 b, 12}$ prepared by radical copolymerization of 4-vinylbiphenyl and divinylbenzene, ${ }^{12 \mathrm{~b}}$ was utilized instead of DTBB, since the former could be removed by simple filtration, and cleaner reaction crudes were obtained. Aryl bromides or chlorides did not react under these conditions. Due to the good result obtained in the ligandless experiment (Table 1, entry 26), we considered it interesting to compare experiments in the absence of any ligand as well as using the bulkier organic base $\mathrm{LiO}-t$-Bu (generated in situ from $\mathrm{Li}$ and $t$-BuOH).

Table 2. Homocoupling of aryl iodides promoted by nickel(0) nanoparticles ${ }^{\mathrm{a}}$

\begin{tabular}{|c|c|c|c|c|c|c|c|}
\hline Entry & $\begin{array}{c}\text { Aryl } \\
\text { iodide }\end{array}$ & Base $^{\mathrm{b}}$ & Ligand $^{\mathrm{C}}$ & $\mathrm{t}[\mathrm{h}]$ & 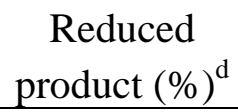 & Coupling product & $\begin{array}{l}\text { Yield } \\
(\%)^{\mathrm{e}}\end{array}$ \\
\hline 1 & & LiOEt & - & 12 & $-\mathrm{g}$ & & 37 \\
\hline 2 & & LiOEt & bathophen ${ }^{\mathrm{f}}$ & 20 & $-\mathrm{g}$ & & $85(54)$ \\
\hline 3 & & $\mathrm{LiO}-t-\mathrm{Bu}$ & - & 48 & $-g$ & & 4 \\
\hline 4 & & LiOEt & - & 24 & 0 & & 88 \\
\hline 5 & & LiOEt & bathophen & 12 & 0 & & 90 \\
\hline 6 & & $\mathrm{LiO}-t-\mathrm{Bu}$ & - & 72 & 0 & & 8 \\
\hline 7 & & LiOEt & - & 12 & 83 & & 17 \\
\hline 8 & & LiOEt & bathophen & 24 & 55 & & $43(24)$ \\
\hline 9 & & $\mathrm{LiO}-t-\mathrm{Bu}$ & - & 48 & 34 & & 2 \\
\hline 10 & & LiOEt & - & 15 & 14 & & 25 \\
\hline 11 & & LiOEt & bathophen & 48 & 34 & & 63 \\
\hline $12^{\mathrm{ME}}$ & & $\mathrm{LiO}-t-\mathrm{Bu}$ & - & 15 & 5 & MeO & 10 \\
\hline 13 & & LiOEt & - & 24 & 0 & & 91 \\
\hline 14 & & LiOEt & bathophen & 15 & 0 & & $60(37)$ \\
\hline 15 & & $\mathrm{LiO}-t-\mathrm{Bu}$ & - & 12 & 0 & & 66 \\
\hline 16 & & LiOEt & - & 24 & 0 & & 54 \\
\hline 17 & & LiOEt & bathophen & 24 & 0 & & $89(43)$ \\
\hline 18 & & $\mathrm{LiO}-t-\mathrm{Bu}$ & - & 72 & 0 & & 17 \\
\hline 19 & & LiOEt & - & 12 & -g & & $84(55)$ \\
\hline 20 & & LiOEt & bathophen & 24 & -g & & 68 \\
\hline 21 & & $\mathrm{LiO}-t-\mathrm{Bu}$ & - & 12 & $-\mathrm{g}$ & & $69(43)$ \\
\hline
\end{tabular}


Table 2. Continued

\begin{tabular}{|c|c|c|c|c|c|c|c|}
\hline Entry & $\begin{array}{c}\text { Aryl } \\
\text { iodide }\end{array}$ & Base $^{b}$ & Ligand $^{\mathrm{c}}$ & $\mathrm{t}[\mathrm{h}]$ & $\begin{array}{c}\text { Reduced } \\
\text { product (\%) }\end{array}$ & Coupling product & $\begin{array}{l}\text { Yield } \\
(\%)^{\mathrm{e}}\end{array}$ \\
\hline 22 & & LiOEt & - & 15 & $-\mathrm{g}$ & & 80 (39) \\
\hline 23 & & LiOEt & bathophen & 48 & $-{ }^{\mathrm{g}}$ & & 70 \\
\hline 24 & & $\mathrm{LiO}-t-\mathrm{Bu}$ & - & 48 & $-{ }^{\mathrm{g}}$ & & 42 \\
\hline 25 & & LiOEt & - & 24 & 0 & & $84(51)$ \\
\hline 26 & & $\mathrm{LiOEt}$ & bathophen & 48 & 0 & & 69 \\
\hline 27 & & $\mathrm{LiO}-t-\mathrm{Bu}$ & - & 48 & 0 & & 59 \\
\hline
\end{tabular}

${ }^{a} \mathrm{Ni}(0)$ nanoparticles were generated from $\mathrm{NiCl}_{2}(1 \mathrm{mmol})$, Li powder $(2 \mathrm{mmol})$, and the copolymer $(0.2 \mathrm{mmol})$ in THF (4 mL) at rt. The homocoupling reactions were carried out at $76{ }^{\circ} \mathrm{C}$.

${ }^{\mathrm{b}} 2 \mathrm{mmol}$ of base. LiOEt and LiO-t-Bu were generated in situ from additional Li powder (2 mmol) and EtOH (2 mmol) or $t$ - $\mathrm{BuOH}$ (3 mmol), respectively.

${ }^{\mathrm{c}} 10 \mathrm{~mol} \%$ ligand.

${ }^{\mathrm{d}}$ GLC yield.

${ }^{\mathrm{e}}$ GLC yield, isolated yield in parenthesis.

${ }_{\mathrm{f}}^{\mathrm{4}}$ 4,7-Diphenyl-1,10-phenanthroline.

${ }^{\mathrm{g}}$ Not detectable.

Depending on the nature of the aryl iodide, the base and the presence or absence of the ligand affected the reaction. With electronically indifferent substituents, best results were obtained in the presence of the ligand (Table 2, entries 2 and 5), albeit the homocoupling of $p$-iodotoluene was also successful in its absence (Table 2, entry 4). Very low yields in these two cases were obtained with the bulkier base $\mathrm{LiO}-t$-Bu (Table 2, entries 3 and 6). Aryl iodides bearing the electron-rich methoxy group led to moderate yields because they underwent hydrodehalogenation as a competing reaction (Table 2, entries 7-12); the best results were obtained in the presence of the ligand (Table 2, entries 8 and 11). Better yields were obtained with substrates containing electron-withdrawing groups: Homocoupling of $p$-fluoroiodobenzene furnished the corresponding biphenyl derivative in good yield with LiOEt in the absence of the ligand (Table 2, entries 13 and 14); with $\mathrm{LiO}-t$-Bu as base a fair yield was achieved at the shortest reaction time (Table 2, entry 15). $p$-Trifluoromethyliodobenzene was better coupled in the presence of the ligand (Table 2, entries 16-18). Iodothiophenes provided the corresponding bithienyls in moderate to high yields (Table 2, entries 19-27): Best results were obtained in the absence of the ligand using LiOEt as base (Table 2, entries 19, 22, and 25). Although the yields are not optimal and isolated yields are rather modest, reduced products resulting from hydrodehalogenation were only detected in the case of methoxy group-bearing aryl iodides.

In general, the reactivity of the in situ generated nickel(0) nanoparticles is more limited with respect to homocoupling of aryl halides than other forms of nickel, ${ }^{4,5}$ because only aryl iodides 
react under the conditions described herein. However, with regard to aryl iodides, similar results were obtained as compared to other nickel-promoted homocoupling reactions, such as those involving $\mathrm{Ni}(\mathrm{COD})_{2}$ in $\mathrm{DMF}$ at $40{ }^{\circ} \mathrm{C}$, ${ }^{4 \mathrm{a}}$ nickel powder (obtained by electrolysis of $\mathrm{NiSO}_{4}$ with $\mathrm{Hg}$ ) in DMF at $120^{\circ} \mathrm{C}$, , electro-generated nickel in DMF at $100{ }^{\circ} \mathrm{C}$, ${ }^{4 \mathrm{e}}$ or the $\mathrm{NiCl}_{2}-\mathrm{CrCl}_{2}-\mathrm{Mn}$ system in THF at room temperature. ${ }^{5 f}$

In conclusion, nickel(0) nanoparticles generated in situ from nickel(II) chloride, lithium powder and a catalytic amount of a polymer-supported arene, can promote the homocoupling of various aryl iodides under relatively mild reaction conditions (THF reflux). The presence of an organic base is fundamental for the reaction to occur, lithium ethoxide generated in situ giving the best results. Bathophenanthroline appears to be the best ligand albeit the homocoupling also takes place in its absence, for some substrates even with better yields and shorter reaction times.

\section{Experimental Section}

General Procedures. Determination of the purity of volatile compounds and chromatographic analyses (GLC) were carried out with a Hewlett Packard HP-5890 instrument equipped with a flame ionization detector and a $30 \mathrm{~m}$ capillary column $(0.32 \mathrm{~mm}$ diameter, $0.25 \mu \mathrm{m}$ film thickness), using nitrogen $(2 \mathrm{~mL} / \mathrm{min})$ as the carrier gas, $\mathrm{T}_{\text {injector }}=275^{\circ} \mathrm{C}, \mathrm{T}_{\text {column }}=60{ }^{\circ} \mathrm{C}(3 \mathrm{~min})$ and $60-270{ }^{\circ} \mathrm{C}\left(15^{\circ} \mathrm{C} / \mathrm{min}\right)$. Flash column chromatography was performed using silica gel 60 (40-60 $\mu \mathrm{m}$ ). THF (Acros, 99.9\%) was used without purification. Commercially available anhydrous nickel(II) chloride (Aldrich) and lithium powder (MEDALCHEMY S. L.) were employed. All aryl iodides were commercially available (Aldrich, Acros, Alfa Aesar, Sigma) and were used without purification. The 4-vinylbiphenyl/divinylbenzene copolymer was prepared by radical copolymerization of the corresponding monomers according to the published procedure. ${ }^{12 \mathrm{~b}}$

\section{Homocoupling of aryl iodides: general procedure}

Nickel chloride (130 mg, $1 \mathrm{mmol}$ ) was added over a suspension of lithium (14 mg, $2 \mathrm{mmol}$ ) and DTBB (13 mg, $0.05 \mathrm{mmol}$ ) or 4-vinylbiphenyl/divinylbenzene copolymer (40 mg, $0.2 \mathrm{mmol}$ ) in THF (4 mL) at room temperature under argon. The reaction mixture, which was initially dark green, changed to black indicating that nickel(0) was formed. For the in situ generation of LiOEt and $\mathrm{LiO}-t-\mathrm{Bu}$, EtOH $(0.12 \mathrm{~mL}, 2 \mathrm{mmol})$ or $t-\mathrm{BuOH}(0.10 \mathrm{~mL}, 3 \mathrm{mmol})$ were added after $10 \mathrm{~min}$, respectively. The reaction mixture was warmed up to THF reflux and monitored by GLC-MS. After the reaction time shown in Table 2, it was filtered through a pad containing silica gel (lower layer) and celite (upper layer) (ca. 3:1). The filtrate was dried over $\mathrm{MgSO}_{4}$ and the solvent evaporated (15 Torr). The resulting residue was analyzed by GLC and/or purified by column chromatography (silica gel, hexane) to give the corresponding pure biaryls. Biphenyl, 4,4'dimethylbiphenyl, 4,4'-dimethoxybiphenyl, 3,3'-dimethoxybiphenyl, 4,4'-difluorobiphenyl, 2,2'bithienyl, 3,3'-bithienyl and 5,5'-dimethyl-2,2'-bithienyl were characterized by comparison of their physical and spectroscopic data with those of commercially available samples (Aldrich). 
The product 4,4'-bis(trifluoromethyl)biphenyl was characterized by comparison of their physical and spectroscopic data with those published in the literature. ${ }^{4 \mathrm{~d}}$

\section{Acknowledgements}

This work was generously supported by the Spanish Ministerio de Educación y Ciencia (MEC; grant no. CTQ2004-01261) and the Generalitat Valenciana (GV; grant no. GRUPOS03/135). P. R. also thanks the MEC for a doctoral fellowship.

\section{References}

1. For a review, see: Hassan, J.; Sévignon, M.; Gozzi, C.; Schulz, E.; Lemaire, M. Chem. Rev. 2002, 102, 1359.

2. See, for instance: (a) Hassan, J.; Penalva, V.; Lavenot, L.; Gozzi, C.; Lemaire, M. Tetrahedron 1998, 54, 13793. (b) Hennings, D. D.; Iwama, T.; Rawal, V. H. Org. Lett. 1999, 8, 1205. (c) Mukhopadhyay, S.; Rothenberg, G.; Gitis, D.; Wiener, H.; Sasson, Y. Tetrahedron 1999, 55, 14763. (d) Venkatraman, S.; Li, C.-J. Org. Lett. 1999, 1, 1133. (e) Kuroboshi, M.; Waki, Y.; Tanaka, H. J. Org. Chem. 2003, 68, 3938. (f) Seganish, W. M.; Mowery, M. E.; Riggleman, S.; DeShong, P. Tetrahedron 2005, 61, 2117.

3. See, for instance: (a) Howarth, J.; James, P.; Dai, J. Tetrahedron Lett. 2000, 41, 10219. (b) Mukhopadhyay, S.; Rothenberg, G.; Qafisheh, N.; Sasson, Y. Tetrahedron Lett. 2001, 42, 6117. (c) Li, J.; Xie, Y.; Jiang, H.; Chen, M. Chem. Commun. 2002, 424. (d) Mukhopadhyay, S.; Yaghmur, A.; Baidossi, M.; Kundu, B.; Sasson, Y. Org. Proc. Res. Devel. 2003, 7, 641. (e) Li, H.-J.; Xie, Y.-X.; Yin, D.-L. J. Org. Chem. 2003, 68, 9867. (f) Park, S. B.; Alper, H. Tetrahedron Lett. 2004, 45, 5515. (g) He, H. S.; Zhang, C.; Ng, C. K.-W.; Toy, P. H. Tetrahedron 2005, 61, 12053.

4. See, for instance: (a) Semmelhack, M. F.; Helquist, P. M.; Jones, L. D. J. Am. Chem. Soc. 1971, 93, 5908. (b) Chao, C. S.; Cheng, C. H.; Chang, C. T. J. Org. Chem. 1983, 48, 4904. (c) Inaba, S.; Matsumoto, H.; Rieke, R. D. J. Org. Chem. 1984, 49, 2093. (d) Lourak, M.; Vanderesse, R.; Fort, Y.; Caubère, P. J. Org. Chem. 1989, 54, 4840. (e) Yasuhara, A.; Kasano, A.; Sakamoto, T. Organometallics 1998, 17, 4754.

5. See, for instance: (a) Takagi, K.; Hayama, N.; Inokawa, S. Chem. Lett. 1979, 917. (b) Courtois, V.; Barhdadi, R.; Troupel, M.; Périchon, J. Tetrahedron 1997, 53, 11569. (c) Adonin, N. Yu.; Ryabinin, V. A.; Starichenko, V. F. Russ. J. Org. Chem. 1998, 34, 286. (d) Leadbeater, N. E.; Resouly, S. M. Tetrahedron Lett. 1999, 40, 4243. (e) Massicot, F.; Schneider, R.; Fort, Y. J. Chem. Res. (S) 1999, 664. (f) Chen, C. Synlett 2000, 1491. (g) Howarth, J.; James, P.; Dai, J. Tetrahedron Lett. 2000, 41, 10319. (h) Massicot, F.; Schneider, R.; Fort, Y.; Illy-Cherrey, S.; Tillement, O. Tetrahedron 2001, 57, 531. (i) de 
Franca, K. W. R.; de Lira Oliveira, J.; Florêncio, T.; da Silva, A. P.; Navarro, M.; Léonel, E.; Nédélec, J.-Y. J. Org. Chem. 2005, 70, 10778.

6. Alonso, F.; Calvino, J. J; Osante, I.; Yus, M. Chem. Lett. 2005, 1262.

7. (a) Alonso, F.; Yus, M. Adv. Synth. Catal. 2001, 343, 188. (b) Alonso, F.; Candela, P.; Gómez, C.; Yus, M. Adv. Synth. Catal. 2003, 345, 275.

8. Alonso, F.; Yus, M. Chem. Soc. Rev. 2004, 33, 284.

9. Alonso, F.; Osante, I.; Yus, M. J. Exp. Nanosci. 2006, 1, 419.

10. Alonso, F.; Osante, I.; Yus, M. Synlett 2006, 3017.

11. (a) Alonso, F.; Osante, I.; Yus, M. Adv. Synth. Catal. 2006, 348, 305. (b) Alonso, F.; Osante, I.; Yus, M. Tetrahedron 2007, 63, 93.

12. (a) Gómez, C.; Ruiz, S.; Yus, M. Tetrahedron Lett. 1998, 39, 1397. (b) Gómez, C.; Ruiz, S.; Yus, M. Tetrahedron 1999, 55, 7017. (c) Candela, P.; Gómez, C.; Yus, M. Russ. J. Org. Chem. 2004, 40, 795. 